\title{
"Los problemas de Jujuy son la tierra y la vivienda". La ley de vivienda obrera rural durante el primer peronismo en Jujuy (Argentina)*
}

Marcelo Jerez

Afiliado institucionalmente al Consejo Nacional de Investigaciones Científicas y Técnicas-CONICET (Argentina). Correo electrónico: mjucasal@gmail.com. El autor es doctor en Historia de la Universidad Nacional de Tucumán (Argentina). Entre sus publicaciones recientes tenemos: "Entre instituciones estatales y la demanda popular. El proceso de adjudicación de las viviendas de un barrio obrero en Jujuy durante el primer peronismo (1946-1955)," en Revista de Historia Americana y Argentina Vol. 51 No. 2 y "La política sanitaria del peronismo en Jujuy (1946-1952). Emilio Navea y la transformación del sistema de salud pública," en Revista Trabajos y Comunicaciones No. 44 (2016). Entre sus temas de interés están Historia de las Políticas Públicas en la primera mitad del siglo XX en la provincia de Jujuy.

Recibido: 22 de septiembre de 2016

Aprobado: 26 de enero de 2017

Modificado: 9 de febrero de 2017

Artículo de investigación científica

DOI: http://dx.doi.org/10.15648/hc.31.2017.10

* Este artículo forma parte del proyecto: "Las políticas sociales del primer peronismo en el noroeste argentino: Jujuy 81946-1955)" financiado por el Consejo Nacional de Investigaciones Científicas y Técnicas (Argentina).

Esta publicación está bajo una licencia Creative Commons Reconocimiento-NoComercial 4.0 
"Los problemas de Jujuy son la tierra y la vivienda". La ley de vivienda obrera rural durante el primer peronismo en Jujuy (Argentina)

\title{
Resumen
}

Esta investigación tiene como objetivo principal el estudio de la ley de viviendas para los trabajadores rurales implementada en una provincia del noroeste argentino, Jujuy, por el primer gobierno peronista (1946-1955). Para ello se presta especial atención al área rural más importante del distrito, la zona azucarera. Proyectos, actores y prácticas son los ejes que orientan este estudio sobre un tema poco explorado por la historiografía: la política habitacional peronista en los espacios rurales de la Argentina.

Palabras clave: Peronismo, Jujuy, política de vivienda, zona rural.

\section{"Jujuy's problems are the Land and the housing". Rural Workers Housing Act during the first period of Peronism in Jujuy (Argentina)}

\begin{abstract}
The main purpose of this research is to study of Rural Workers Housing Law in a province of northwestern Argentina, Jujuy, during peronism (1946-1955). For this reason, this study focuses on the most important rural area; the sugar zone. Projects, actors and practices are the key concepts that guide this investigation on a rare topic in Argentine historiography: the housing policy in Peronism of rural areas of Argentina.
\end{abstract}

Keywords: Peronism, Jujuy, housing policy, rural zone.

“Os problemas de Jujuy são a terra e a moradia”. A lei de moradia operária rural durante o primeiro peronismo em Jujuy (Argentina)

\section{Resumo}

Esta pesquisa tem como objetivo principal o estudo da lei de moradias para os trabalhadores rurais implementada em uma província do noroeste argentino, Jujuy, pelo primeiro governo peronista (1964-1955). Para se dá atenção especial à área rural mais importante do distrito, a zona açucareira. Projetos, atores y práticas são os eixos que orientam essa pesquisa sobre um tema pouco explorado pela historiografia: a política habitacional peronista nos espações rurais da Argentina.

Palavras-chaves: Peronismo, Jujuy, política habitacional, zona rural. 
“Les problèmes de Jujuy sont la terre et le logement". La loi sur le logement ouvrier rural pendant le premier péronisme à la province de Jujuy (Argentine)

\section{Résumé}

Cette recherche a pour but l'étude de la loi sur le logement pour les travailleurs ruraux mise en place dans une province du nord-est argentin, Jujuy, par le premier gouvernement péroniste (1946-1955). À cette fin, on fait très attention à l'aire rurale la plus importante du district, la zone sucrière. Des projets, des acteurs et des pratiques sont les axes qui guident cette étude sur un sujet peu exploré par l'historiographie : la politique péroniste sur le logement dans les espaces ruraux d'Argentine.

Mots clés: Péronisme, Jujuy, politique sur le logement, zone rurale.

\section{INTRODUCCIÓN}

El 4 de junio de 1943 un golpe militar ponía fin al régimen conservador en la Argentina y establecía un gobierno de facto. Con su designación al frente del Departamento de Trabajo, más adelante convertido en Secretaría, Juan Domingo Perón hacía su aparición en la escena política nacional iniciando, desde allí, un acercamiento con el mundo laboral. Este vínculo sería fundamental para lanzar su candidatura presidencial en las elecciones democráticas acordadas para inicios de 1946. Elegido presidente, Perón pronto procedería a conformar un Estado de carácter nacionalista, popular, dirigista y benefactor, consolidando a través de diversas políticas la imagen de un gobierno atento a las necesidades de los trabajadores, tanto en el espacio urbano como rural.

En este contexto, en la provincia de Jujuy, ubicada en el noroeste de la Argentina, un medio local publicaba, luego de aquel proceso electoral, una entrevista a Miguel Tanco, líder de la fuerza política que en este distrito había brindado su apoyo a Perón, titulada "Los problemas de Jujuy son la tierra y la vivienda"1. Aquellas palabras del caudillo, daban cuenta de las problemáticas, de larga data, que más preocupaban al gobierno electo y a las que prestaría especial atención en todo el territorio provincial en general y en la zona rural en particular.

1 Álbum del Nuevo Jujuy (Salta: Talleres Gráficos La Provincia, 1946), 46. 
En efecto, hacia el comienzo de la experiencia peronista, Jujuy, en oposición a lo que ocurría en el país en su conjunto, presentaba una población eminentemente rural, rasgo que compartía con la región del Noroeste argentino. Su estructura agraria, a su vez, estaba signada por la existencia de una importante concentración de la propiedad, especialmente en las tierras altas y en el oriente de las tierras bajas de la provincia. Estas regiones presentan particularidades propias que es necesario tener en cuenta para facilitar la comprensión del contexto en el que se desarrolla el tema que nos ocupa. Intentaremos especificarlas de manera sintética.

En Jujuy, tanto por sus características naturales como por sus rasgos socioculturales, pueden diferenciarse nítidamente dos grandes regiones internas llamadas tierras bajas y tierras altas. Estas últimas ocupan el noroeste del distrito y en ellas se distinguen dos ambientes, con mayor poblamiento en tiempos de la Conquista española, y donde tempranamente se entregaron mercedes de tierras y encomiendas. En primer lugar, la Quebrada de $\mathrm{Hu}-$ mahuaca, un corredor natural encerrado entre montañas que comunica las tierras bajas con las altas; y la Puna, que se encuentra por encima de los 3000 metros sobre el nivel del mar.

En esta amplia área, el advenimiento de la República no implicó demasiados cambios en el estatus de la propiedad, dado que no hubo tierras concedidas a los indígenas ni a los pueblos. En consecuencia, buena parte de la población originaria asumió el carácter de "arrenderos" de los propietarios de las grandes haciendas existentes. La supresión de la encomienda, además, conllevó a que, de hecho, el antiguo tributo fuera transformado en la provisión de mano de obra por la "obligación de servicio personal" que implicaba el régimen de arrendatario, junto al pago de un canon por el derecho de pastaje o por practicar la agricultura, donde la naturaleza lo permitía.

La Puna exhibía tal vez el caso más extremo de este fenómeno en Jujuy ${ }^{2}$. Con temperaturas anuales predominantemente bajas, esta zona presentaba escasas condiciones para la agricultura. La mayoría de sus habitantes, practicaban la cría de ganado -tales como ovinos o camélidos- vinculada a una economía de subsistencia, reproduciendo antiguas prácticas culturales

2 Álbum del Nuevo Jujuy (Salta: Talleres Gráficos La Provincia, 1946), 46. 
y modos de vida que los diferenciaba de las sociedades asentadas en otras regiones del distrito, como las de las tierras bajas ${ }^{3}$. Estas, por su parte, se hallaban integradas por los Valles Centrales, en el centro-sur de la provincia, donde se encuentra la ciudad capital, San Salvador de Jujuy, y, hacia el este, por los cálidos y húmedos Valles Subtropicales.

Precisamente sería esta última región -por sobre los Valles Centrales donde las grandes propiedades tempranamente fueron subdividiéndose-, el otro espacio caracterizado por el latifundio. Pero a diferencia de las tierras altas, tal tendencia sería el resultado de un proceso acentuado con la modernización azucarera, fundamentalmente, en los departamentos de San Pedro y Ledesma. En la época de la colonia esta zona era considerada de frontera con el Chaco, habitada por indígenas de economía cazadora recolectora, y penetrada por la conquista española tardíamente, en la segunda mitad del siglo XVIII, con el asentamiento de misiones, fuertes y haciendas.

Recién a partir de la década de 1870, esta región, que había sido marginal en la provincia, adquiriría relevancia con la modernización técnica de las fábricas de azúcar, emprendidas inicialmente con capitales salteños y jujeños, proporcionando así la base de integración de Jujuy al mercado capitalista nacional. La puesta en marcha de los modernos ingenios - de los cuales los más importantes eran La Esperanza en San Pedro y Ledesma en el departamento homónimo-, valorizó la propiedad, la que en poco tiempo concentrarían en altos porcentajes, mientras que su producción comenzaría a generar rentas cada vez más relevantes para el fisco.

Para responder a las necesidades estacionales de mano de obra de esta agroindustria, al tradicional reservorio de trabajadores que brindaba el espacio chaqueño argentino y boliviano, se sumaría el de las tierras altas jujeñas. Lograr la incorporación de estas poblaciones requirió distintas estrategias. Una de ellas, la empleada a fines de los años de 1920 por el inge-

3 La concentración de la propiedad por parte de los españoles y luego criollos fue mayor en la Puna que en la Quebrada de Humahuaca, donde a fines del siglo XIX se produjo un proceso de subdivisión y adquisición que posibilitó a varios particulares adquirir su propiedad. Ana Teruel y María Teresa Bovi, "El ordenamiento de la propiedad territorial en Jujuy. Del antiguo régimen a la modernidad" en Problemas nacionales en escalas locales. Instituciones, actores y prácticas de la modernidad en Jujuy, dir por Ana Teruel (Rosario: Prohistoria, 2010), 95-101. 
nio San Martín del Tabacal en la vecina provincia de Salta, consistió en la adquisición de grandes extensiones de tierras en la zona circundante, que incluiría algunas áreas de la Puna donde sus habitantes se transformaron en arrenderos, debiendo pagar las rentas con su propio trabajo.

Los ingenios jujeños, en cambio, para el reclutamiento de trabajadores se valdrían de los servicios del contratista o "conchabador". Esta figura habitualmente era a la vez juez de paz, comisario o caudillo político y, desde esta posición, desplegaba una serie de mecanismos coercitivos para asegurar a las fábricas la mano de obra indígena. La situación se agravaría durante la década de 1930, cuando los propietarios de los ingenios de las provincias norteñas pasaron a ocupar puestos claves en las estructuras del poder político. Este fue el caso de Herminio Arrieta, dueño del ingenio Ledesma y líder indiscutido del partido conservador jujeño.

Pero además de la agroindustria azucarera otra actividad se constituiría en una importante fuente de trabajo asalariado, la producción minera. En los años previos a la experiencia peronista dos eran los yacimientos más importantes ubicados en la Puna: El Aguilar, de capitales norteamericanos, y la Compañía Minera Pirquitas, constituida por capitalistas locales. Para entonces, cada una de estas empresas ocupaba alrededor de mil obreros provenientes de la zona. Los ingresos por esta labor, en general voluntaria, les permitían a los trabajadores pagar los arriendos, aunque eran sometidos, como en la zona azucarera, al sistema extorsivo de las proveedurías.

Si bien la actividad minera se hallaba en franco crecimiento, hacia el período que nos ocupa, fue claro que no igualaba el auge de la producción azucarera que reunía a la masa laboral más importante de la provincia, con alrededor de cinco mil obreros en la época de zafra en tan solo un ingenio. Sin embargo, como sostiene Campi, esta prosperidad mostraba también sus "contrastes", patentes en las deplorables condiciones laborales y de vida existentes en el interior de aquellos "enclaves". Su más dramática manifestación se plasmaba en la pobreza, el atraso y la miseria de las precarias construcciones improvisadas como viviendas de los trabajadores más humildes ${ }^{4}$.

4 Desde tiempos prehispánicos, las características geográficas andinas habían llevado a la conformación de modelos de organización de la producción basados en el aprovechamiento estratégico de las variantes microecológicas sobre la base de relaciones de reciprocidad, que implicaban, a la vez, 
El problema de la vivienda obrera ciertamente fue un tema que ocupó un lugar prioritario en la agenda del grupo político liderado por Tanco ${ }^{5}$. Como en otros puntos de la Argentina, en la época, la provincia evidenciaba pésimas condiciones habitacionales, no solo en el ámbito urbano sino también en el rural. En esta zona, aquel grupo político prestó especial atención, junto a los añejos reclamos de los campesinos arrendatarios, a las necesidades de los numerosos trabajadores de la minería y el azúcar. Ello respondía, en buena medida, a su intención de captar a los componentes obrero y campesino para constituirlos en las bases sociales de su poder político. No obstante, en el lapso previo a 1943 no les fue posible impulsar un conjunto de medidas oficiales que atendiesen estas problemáticas ${ }^{6}$..

La etapa abierta con la llamada Revolución del 4 de Junio y el posterior surgimiento del peronismo, abriría sin duda una nueva coyuntura política. Pero aunque el estudio de la intervención del Estado peronista en materia de vivienda en Jujuy ha sido una temática muy trabajada, el análisis tendió a centrarse principalmente en el ámbito urbano ${ }^{7}$. Por ende, poco se conoce sobre lo acontecido en aquella compleja zona rural, particularmente en áreas donde ciertas actividades económicas concentraron un número significativo de trabajadores.

Con el propósito de contribuir a llenar este vacío, el presente trabajo histórico analiza en la provincia de Jujuy una de las medidas más emblemá-

formas colectivas de acceso a la tierra y al uso de diversos recursos como pasturas y aguadas. Además existió en la Puna un activo tráfico regional a corta y larga distancia. Las rutas transitadas por hombres, caravanas de llamas y bienes, conectaban a las comunidades jujeñas con el altiplano boliviano, los oasis del norte chileno y las selvas chaqueñas. La infinidad de caminos y sendas que surcaban las regiones internas de Jujuy permitía a los puneños llegar a los diferentes pisos ecológicos y complementar su economía.

5 Daniel Campi, "Contrastes cotidianos. Os engenhos açucareiros do norte da Argentina como complexos sócio-culturais”, Varia Historia Vol. 25 (2009): 247.

6 El líder del radicalismo yrigoyenista jujeño, Miguel Tanco -ya desde los comienzos de su actividad pública en 1921- reivindicaba la lucha de los sectores más humildes, colocando en un lugar privilegiado a cuestiones como la del latifundio en las tierras altas jujeñas o las mejoras en las condiciones laborales y de vida de los trabajadores. Con ello, procuraba hacerse de firmes apoyos, desplegando una intensa actividad de organización de bases sociales, recorriendo personalmente distintos pueblos y ciudades de la provincia. Su perfil popular opuesto al de los elegantes "caballeros notables", miembros del sector conservador, contribuyó a ganarse la adhesión de buena parte de la población campesina y obrera.

7 Ya desde los años de 1920, diversos proyectos legislativos serían elaborados para tratar estas cuestiones aunque sin éxito, pues tocaban de cerca los intereses de importantes propietarios, como se ha dicho, muy vinculados al sector político gobernante. 
ticas implementadas por el gobierno peronista en la zona rural: la Ley 1814, denominada ley de vivienda obrera. La misma, sancionada a fines de 1947, establecía la obligatoriedad de las empresas instaladas en el distrito de proporcionar viviendas dignas a sus trabajadores y familias. Estos establecimientos, a los que hacía referencia la norma, debían reunir una cantidad importante de obreros, en alusión implícita a aquellos vinculados a la producción minera y, sobre todo, azucarera.

Resulta interesante señalar que esta investigación al centrarse en el ámbito de empresas tan significativas en el campo económico y político de la provincia, así como de la región, conlleva ciertamente una particularidad relevante respecto de la vivienda rural en general. Mejorar las condiciones habitacionales de aquella población trabajadora. fue uno de los viejos objetivos de la dirigencia tanquista que se propuso concretar una vez en el gobierno, luego del triunfo electoral de 1946.

Conviene destacar que en Jujuy, durante el lapso precedente, el conservadurismo a través de diversas medidas represivas, como en muchos otros puntos del país, se había ocupado con éxito de desmantelar toda intención de organización sindical obrera en los centros mineros como azucareros. Por ello, la ley en cuestión resulta especialmente expresiva de un programa social diseñado por el tanquismo, que se había constituido en el portavoz de las reivindicaciones de aquellos sectores laborales más sumergidos.

La idea que defendemos en este trabajo sostiene que la política de vivienda peronista dirigida a la población rural de la provincia jujeña estuvo claramente diferenciada de la aplicada en los centros urbanos. Ello se hallaba estrechamente vinculado con las características y problemáticas propias que presentaba dicha área. Para atender las mismas, aquella administración recuperaría viejos programas elaborados durante la etapa anterior que habían sido postergados por un gobierno conservador, muy ligado con el poder económico de los ingenios azucareros.

Así, frente a la cuestión específica de la vivienda, mientras en los espacios urbanos las iniciativas oficiales tendieron en gran parte a la intervención directa, a través de la construcción estatal de unidades habitacionales, en la zona rural se delegaría esta tarea a los establecimientos mineros y azu- 
careros. La norma que nos ocupa perseguiría tal objetivo y se constituiría en una reglamentación relevante como inédita a nivel provincial, e incluso nacional, si bien su implementación no estaría nada exenta de revisiones, tensiones y de un férreo control gubernamental para asegurar su cumplimiento.

De esta manera, surgen ciertos interrogantes: ¿qué rasgos presentaban las condiciones habitacionales en el ámbito rural de Jujuy en el lapso previo al surgimiento del peronismo? Luego, a partir del gobierno justicialista, ¿dicha cuestión ocupó un lugar prioritario en la agenda oficial? ¿Cuáles fueron las modalidades que asumió aquella intervención estatal? ¿Qué características exhibió la ley abordada? ¿Qué otras normas la complementaron? ¿Qué actores políticos participaron en ese proceso? ¿Qué conflictos o tensiones pueden evidenciarse en su implementación? ¿Estas medidas solucionaron la problemática de la vivienda en el área rural?

En procura de responder estas preguntas, a continuación nos dedicamos a indagar sobre la intervención habitacional peronista en aquellos tradicionales centros productivos jujeños ${ }^{8}$. Iniciamos nuestro estudio analizando el contexto sociopolítico del distrito, para luego abordar las principales iniciativas oficiales en torno a la cuestión de la vivienda. Finalmente nos ocupamos de la Ley 1814, sus disposiciones y correcciones, develando asimismo las implicancias que asumió su ejecución.

\section{Contexto Sociopolítico}

Desde un punto de vista geográfico, como se ha dicho, en Jujuy se distinguen cuatro regiones internas: en las tierras altas se encuentran la Quebrada de Humahuaca y la Puna; en las tierras bajas, los Valles Centrales, donde se emplaza la capital del distrito, y, en un predominante ambiente de selvas húmedas en las laderas de las montañas, los Valles Subtropicales, núcleo

8 Marcelo Jerez es el que más contribuciones ha brindado sobre esta temática en Jujuy en trabajos como: "El gobierno de Alberto Iturbe (1946-1952): La política de vivienda del primer peronismo en Jujuy", Revista Cuadernos No 41 (2012): 303 "Notas críticas en torno a la política habitacional del primer peronismo en Jujuy (1946-1955)", Revista de Estudios Marítimos y Sociales N 5/6 (2013): 134 "Proyectos, debates y críticas en torno a la vivienda obrera en el Noroeste argentino. San Salvador de Jujuy (1930-1945)," VI Anuario de la Escuela de Historia Virtual No 6 (2014): 100. 
principal de la producción azucarera ${ }^{9}$. Fue precisamente el desarrollo de esta actividad, sobre todo a partir de la segunda mitad de 1920, uno de los factores que incidió de modo relevante al crecimiento demográfico de la provincia.

Sin duda, en las primeras décadas del siglo XX, la producción azucarera fue la mejor alternativa de articulación de las provincias del Noroeste argentino con la expansión económica, basada en la exportación de bienes primarios, que experimentaba el área pampeana. Asimismo, contribuyeron al aumento poblacional de Jujuy la gran minería explotada en la Puna -en la que participaron, además de firmas locales y extranjeras, empresarios azucareros- y de cierta producción agraria de importancia -como el tabaco- en los Valles Centrales.

Pero esta evolución demográfica muy pronto reveló también serias deficiencias, principalmente, en las áreas de salud, educación y vivienda. Un hecho ilustrativo de ello fue que en estos años diversas localidades del distrito carecían de centros asistenciales u hospitales ${ }^{10}$. Por su parte, los escasos nosocomios existentes se caracterizaban por la falta de insumos elementales para su funcionamiento debido a los escasos recursos financieros que el gobierno provincial destinaba para sostenerlos. A estos problemas se sumaban las notorias dificultades en la provisión de servicios públicos

9 Los estudios centrados en estos espacios son amplios y han abordado distintas temáticas, haciendo especial hincapié en las condiciones laborales y de vida en la zona azucarera. Sin embargo, más allá de sus notables aportes, la mayoría de estas investigaciones se ocupó del período de conformación y "despegue" de aquella agroindustria, a fines del siglo XIX y principios de la centuria siguiente, sin adentrarse en los años peronistas. Entre dichos trabajos pueden citarse: Daniel Santamaría, Azúcar y sociedad en el Noroeste argentino (Buenos Aires: IDES, 1986); Daniel Campi y Marcelo Lagos, "Auge azucarero y mercado de trabajo en el Noroeste Argentino, 1850-1930" Revista Andes $N^{\circ} 6$ (1995); Marcelo Lagos, "El mundo del trabajo en los Ingenios azucareros en la etapa de inserción al mercado nacional (1920-1940)", en Jujuy: arqueología, historia, economía, sociedad, comp. Daniel Santamaría (Jujuy: Ediciones Cuadernos del Duende, 2005); Ana Teruel, Marcelo Lagos y Leonor Peirotti, "Los valles orientales subtropicales: frontera, modernización azucarera y crisis", en Jujuy en la Historia. De la colonia al siglo XX, dir Ana Teruel y Marcelo Lagos (Jujuy: Ediunju, 2006), 435464.

10 A su vez la provincia de Jujuy se halla integrada por los siguientes departamentos: Capital, San Antonio y El Carmen (en los Valles Centrales); Ledesma, San Pedro, Valle Grande y Santa Bárbara (en los Valles Subtropicales); Humahuaca, Tilcara y Tumbaya (en la Quebrada); Cochinoca, Rinconada, Yavi, Susques y Santa Catalina (en la Puna). 
básicos (como agua potable, cloacas, luz eléctrica), realidad que afectaba a numerosos poblados, urbanos como rurales.

Las enfermedades recurrentes por entonces en Jujuy eran el paludismo y la tuberculosis, mientras las tasas de mortalidad materna e infantil de la provincia se encontraban entre las más altas del Noroeste y del país ${ }^{11}$.. Los Valles Subtropicales y la Puna eran las regiones donde se registraban los índices más críticos en ese sentido. A estos alarmantes datos sanitarios se añadían los elevados niveles de analfabetismo del distrito, especialmente en jóvenes y adultos ${ }^{12}$. Una vez más, las tierras altas y la zona azucarera sobresalían en la frecuencia de esta problemática ${ }^{13}$.

De igual modo, en este período, comenzaba a cobrar cada vez más relevancia la problemática de la vivienda. Así lo reflejaban los altos índices de hacinamiento individual, consistente en más de cuatro miembros de una familia durmiendo todos en una misma pieza. Por otro lado, el censo de 1947 registraba que en Jujuy solo un 30 \% de la población era propietaria de su casa. Este porcentaje se constituía en uno de los más bajos de la región y del país, superado únicamente por la Capital Federal con un valor que descendía al $18 \%{ }^{14}$. Los medios de comunicación de la época en sus artículos asiduamente reflejaban las graves consecuencias de esta cuestión.

Si bien la repercusión del problema habitacional en las ciudades era más notoria, ello no implicó que en la zona rural de la provincia la realidad fuera menos preocupante, especialmente en aquellas áreas que concentraban una importante cantidad de trabajadores, tales como la Puna y, principalmente, los Valles Subtropicales. Al respecto, en 1943, un mes después de la llamada Revolución del 4 de Junio, un matutino señalaba que en los es-

11 De este modo, por ejemplo en la ciudad puneña de La Quiaca, tanto los médicos como la prensa, constantemente solicitaban una mayor presencia del Estado. Diario Crónica Jujuy, 28 de junio de $1935,5$.

12 Diego Armus y Susana Belmartino, "Enfermedades, médicos y cultura higiénica", en Nueva Historia Argentina. Crisis económica, avance del Estado e incertidumbre política (1930-1943), dirigido por Alejandro Cattaruzza (Buenos Aires: Sudamericana, 2001), 291-300.

13 Censo General de la Nación, año 1947. Censo de Población, (Buenos Aires, 1951).

14 Entre las principales causas se hallaban el abandono escolar por trabajo y la falta de establecimientos adecuados. IV Censo Escolar, del Analfabetismo y de la Vivienda del año 1943 (Buenos Aires, 1948). 
tablecimientos mineros desde hacía tiempo se hallaba ausente "todo tipo de control en materia de leyes de trabajo", siendo además deplorables las condiciones de vida del obrero ${ }^{15}$.

En la zona azucarera la situación no era más alentadora. Nuevamente los registros censales nos brindan interesantes datos sobre las condiciones habitacionales de esta población en particular. Así en 1947 los departamentos de Ledesma y San Pedro mostraban la mayor proporción de inquilinos de la provincia (92\% y $94 \%$ respectivamente). Fue claro como estas personas correspondieron, en su mayoría, a los trabajadores de los ingenios donde, si bien los dueños de estos establecimientos construían algunas viviendas para albergar a sus obreros, no se les entregaba su propiedad ${ }^{16}$.

Asimismo, en un contexto provincial donde el hacinamiento individual era más frecuente y significativo, los guarismos en la zona rural se agudizaban. De esta manera, mientras en el área urbana aquel fenómeno afectaba al 48 $\%$ de las familias censadas, en el ámbito rural el porcentaje ascendía al 58 $\%$. Entre los distritos que registraban los mayores casos se hallaban aquellos pertenecientes al área azucarera donde más de la mitad de las personas registradas padecía de hacinamiento individual, con cerca de un $60 \%{ }^{17}$.

A partir de estos valores, es dable suponer cómo muchos de los trabajadores de los principales ingenios azucareros de la provincia (como Ledesma y La Esperanza), a comienzos de la década de 1940, no solo no eran propietarios de sus viviendas sino que por lo general vivían hacinados en residencias sumamente precarias. Esta situación afectaba principalmente a los obreros estacionales, cuyo número duplicaba ampliamente al de los permanentes. Así en época de zafra, se estima que en conjunto alrededor de diez mil personas desarrollaban sus labores en aquellos dos ingenios más importantes.

15 El hacinamiento individual era más frecuente en la provincia que el hacinamiento colectivo (más de cuatro familias que compartían una casa). Así de las familias censadas, aproximadamente la mitad, y en algunos casos muchas más, se hallaban residiendo en una única habitación. Marcelo Jerez, "Características habitacionales en Jujuy, Argentina, en la primera mitad del siglo XX", Revista América Latina en la Historia Económica N 2 (2012): 177-186.

16 Diario Crónica Jujuy, 14 de julio de 1943, 5.

17 Marcelo Jerez, "Características habitacionales en Jujuy”, 180. 
Debe señalarse que cerca del $80 \%$ de estos trabajadores, junto a sus familias, habitaban en modestas residencias de un solo ambiente, las que en general carecían de excusados individuales y provisión de agua potable, recurriendo para ello a las acequias más cercanas. Campi brinda más precisiones al respecto afirmando que, por entonces, mientras los empleados permanentes ocupaban casas medianamente confortables, los transitorios o zafreros, mucho más numerosos, moraban en construcciones muy humildes. Estas eran los llamados "cuartos, conventillos, pabellones o galpones", cuando no se instalaban en "rancherías o tolderías" en las inmediaciones de las fábricas ${ }^{18}$.

Una característica distintiva de los ingenios de Jujuy, al igual que los de Salta, fue su capacidad de monopolizar grandes extensiones de tierras aptas para las plantaciones, a diferencia de lo acontecido en Tucumán donde la actividad económica se desarrolló en un régimen signado por el minifundio $^{19}$. De allí que, especialmente, en los establecimientos jujeños todo era de su propiedad. Así, no solo dotar de una vivienda (precaria o no) a sus trabajadores constituía un acto voluntario de los propietarios de estas empresas, a lo cual no se encontraban legalmente obligados de modo alguno, sino que además, en caso de hacerlo, poseían total libertad para desalojarlos de la misma en cualquier momento y sin previo aviso ante cualquier falta considerada grave ${ }^{20}$.

El sector gobernante de la provincia, en la etapa previa al surgimiento del peronismo, era consciente de la situación de estos trabajadores rurales. Sin embargo, fueron escasas las respuestas oficiales a través de normas o reglamentaciones que tendieran a mejorar aquella realidad. Sin duda, mucho tuvo que ver el contexto imperante, signado por el indiscutible poder político del partido conservador, estrechamente vinculado, por otro lado, a los ingenios azucareros de la provincia.

18 Marcelo Jerez, "Características habitacionales en Jujuy", 177.

19 En este marco, la preocupación de la dirigencia tanquista -luego en el gobierno- por la situación habitacional de estos trabajadores, residiría no sólo en brindarles un mayor acceso al bienestar sino también en mejorar sus deficientes condiciones sanitarias. Daniel Campi, "Contrastes cotidianos", 249.

20 Daniel Campi y Marcelo Lagos, “Auge azucarero”, 181-182. 
Estas empresas no solo se habían convertido en aquellos años en habituales prestamistas del Estado provincial, sino que sus propietarios estaban relacionados directamente con la cúpula dirigencial conservadora. Este fue el caso de Herminio Arrieta, dueño del ingenio Ledesma y cabeza de aquel partido en el ámbito local, quien se había desempeñado además, entre otros cargos, como senador nacional y luego, hasta el golpe militar de 1943, como diputado nacional ${ }^{21}$.

Por su parte el radicalismo, en especial de signo yrigoyenista y liderado por Miguel Tanco, se constituiría en el principal adversario político del conservadurismo, con el que dirimiría una conflictiva y, por momentos violenta, competencia partidaria. Este grupo político, al hacerse eco de los reclamos de los sectores más sumergidos, contaría con un gran ascendiente popular. Según los medios partidarios aquel caudillo encarnaba al "hombre que levantará al obrero y hará feliz la vida del pueblo", el "defensor del proletariado y enemigo de los patrones"22.

Dentro de su plataforma política, los proyectos destinados a optimizar las condiciones laborales y de vida de los trabajadores no estarían ausentes ${ }^{23}$. No obstante, pese a que en diversas oportunidades el radicalismo pudo acceder al gobierno ${ }^{24}$, le costó mucho desenvolverse frente al constante obstruccionismo del bando opositor. El propio Tanco fue un habitual des-

21 Si bien la ley que nos ocupa en este estudio no trataba la regulación de estas situaciones, el aumento del control del Estado sobre las relaciones laborales experimentado a partir de 1946, a través de las continuas visitas de inspectores de agencias estatales, contribuyó sin duda a limitar todo este tipo de arbitrariedades.

22 Adriana Kindgard, Alianzas y enfrentamientos en los orígenes del peronismo jujeño (Jujuy: Ediunju, 2001), 60-62.

23 María Silvia Fleitas, "Reforma? Revolución? En torno a la lucha política a fines de la década radical en Jujuy", en Del Centenario al peronismo. Dimensiones de la vida política argentina, comp. por María Inés Tato y Martín Castro (Buenos Aires: Imago Mundi, 2010), 145-147.

24 Este sector político, siguiendo los lineamientos generales fijados por Yrigoyen respecto de los conflictos obreros y la cuestión social, se propondría hacer intervenir al Estado como árbitro entre el capital y el trabajo, preocupándose por la sanción de leyes sociales. Dentro de sus proyectos legislativos más destacados, en los años de 1920 y 1930, pueden mencionarse aquellos sobre accidentes de trabajo, prohibiendo el pago de salarios de trabajadores y jornaleros en vales o fichas, acerca de la asistencia médica obligatoria y permanente en los establecimientos donde el trabajo representase algún riesgo para los obreros así como el programa de creación de la vivienda obrera elaborado en 1927. Diario La Vanguardia Jujuy, 9 de mayo de 1930. 
tinatario de estas maniobras ${ }^{25}$. Uno de sus últimos golpes recibidos acontecería en 1929, cuando habiendo sido elegido gobernador tendría que entregar el mando al año siguiente como consecuencia del levantamiento militar encabezado por Uriburu en Buenos Aires. Se iniciaba así en este distrito, como en el resto del país, una década caracterizada por el retorno de los conservadores al gobierno.

Durante estos años, el vínculo entre el conservadurismo y los propietarios de los ingenios azucareros hallarían su más acabada expresión en Jujuy. Además de contar con el dueño del ingenio Ledesma como el líder indiscutido de aquel sector político, la influencia de esta agroindustria llevaría a individuos de su esfera a alcanzar altos puestos políticos. Así por ejemplo, ya en 1932, la mayoría de los legisladores provinciales estaban relacionados con aquellas compañías, a través de distintas funciones: médicos, abogados, gerentes de secciones y hasta contratistas de peones. Este dominio del control de la estructura del Estado se mantendría, a través del fraude electoral, con el claro propósito de instrumentar el poder político de acuerdo a los intereses de los capitalistas azucareros ${ }^{26}$.

\section{El primer peronismo jujeño: "Los problemas de JujuY SON la TIERRA Y LA VIVIENDA"}

Luego del derrocamiento de Tanco en 1930, el conservadurismo ocupaba nuevamente el gobierno. Durante esta década, su hegemonía política sería innegable en la provincia aun con la decisión del presidente Ortiz, en 1940, de abandonar los "vicios del sufragio" que permitiría el acceso al gobierno del radical Raúl Bertrés. Su gestión, de todos modos, a los dos años concluiría abruptamente por una intervención federal que allanaría el retorno de los conservadores al gobierno. El radicalismo protestaría airadamente contra esta medida nacional propiciada "por una minoría que representaba en la Legislatura los intereses de la oligarquía del azúcar"27.

25 El período radical en la provincia se desarrolló bajo las administraciones de Carrillo (abril 1918-abril 1921), Córdova (abril 1921-enero 1924), Tanco (septiembre 1929-septiembre 1930) y Bertrés (mayo 1940-enero 1942).

26 Las alianzas entre antipersonalistas y conservadores, al igual que sufragios poco transparentes, ya desde comienzos de la década de 1920 le habían dificultado a Tanco su elección como gobernador y luego como diputado nacional.

27 Adriana Kindgard, Alianzas y enfrentamientos, 64-68. 
El año 1943 comenzaba sin grandes preocupaciones para el conservadurismo. Nada hacía prever los importantes cambios políticos que algunos meses después sobrevendrían. El 4 de junio, en Argentina el régimen conservador era derrocado por un golpe militar. En Jujuy, las nuevas autoridades de facto desde un principio proclamaban su decidida intención de hacer cumplir sus principales postulados, haciendo un fuerte hincapié en la moral del sector dirigente. En el plano social, mientras tanto, se asumía la tarea de constituir al Estado en un mediador entre el capital y el trabajo, comprometiéndose además a ocuparse de las principales demandas popu$\operatorname{lares}^{28}$.

En esta nueva coyuntura, comenzarían a hacerse patente los vínculos cada vez más cercanos entre esta administración y el radicalismo yrigoyenista. Fue así como viejas figuras como Jorge Villafañe o Teodoro Saravia, comenzaban a ocupar cargos dentro del gobierno de intervención. Pero también fue el momento para jóvenes dirigentes, como Alberto Iturbe, Carlos Snopek o José Humberto Martiarena ${ }^{29}$. Todos ellos cumplirían una labor relevante, colocando al tanquismo otra vez en el centro de la escena política provincial. Hacia 1945, los acontecimientos suscitados a nivel nacional brindarían a este grupo político un nuevo y particular contexto.

En Buenos Aires, luego del emblemático 17 de octubre, se conformaba el Partido Laborista que apoyaría electoralmente al coronel Juan Domingo Perón, mientras en Jujuy el nombre de Tanco se hallaba entre los más serios candidatos capaces de representar al nuevo partido. No obstante, este viejo caudillo encabezaría un nuevo espacio político separado del laborismo, que tomaría el nombre de Unión Cívica Radical Yrigoyenista, desde donde participaría en las elecciones de febrero de 1946 brindando su apoyo a Perón ${ }^{30}$.

Para esta contienda electoral, Alberto Iturbe sería designado candidato a

28 Manifiesto de la Convención de la U.C.R. de Jujuy al pueblo de la provincia, mayo de 1942, citado en Adriana Kindgard, Alianzas y enfrentamientos, 88.

29 Jujuy. Intervención Federal: Seis meses de gobierno (Jujuy: Imprenta Kraft, 1945), 5.

30 Rubén Hidalgo e Ignacio Martínez Loran, Familia y tradición en el Norte argentino (Buenos Aires: Editorial Provincias Argentinas, 1964), 28. 
gobernador de la provincia de Jujuy, tras la decisión de Tanco de competir por una banca en el Senado de la Nación. La victoria de la fuerza política que apoyaba a Perón en Jujuy sería contundente. No solo obtendrían la gobernación de la provincia, sino también la mayoría de las bancas provinciales y nacionales. Ello sin duda confirmaba el importante ascendiente del tanquismo y de Perón en Jujuy, este último logrado a través de sus iniciativas sociales desde la Secretaría de Trabajo.

El flamante gobernador sería acompañado por aquel equipo político integrado por nuevos y antiguos dirigentes. Un viejo militante radical, el ingeniero Juan José Castro, asumía como vicegobernador mientras el joven abogado José H. Martiarena se hacía cargo del Ministerio de Gobierno, Justicia e Iinstrucción Pública. Este último, a los pocos días de su designación, manifestaba un sentir compartido por todo el sector gobernante: el compromiso de solucionar tres de los más grandes problemas de la provincia; "sanidad, educación y vivienda"31. Esta afirmación refrendaba una vez más las grandes deficiencias que la provincia exhibía en aquellas tres áreas durante estos años.

La cuestión habitacional constituía desde hacía tiempo ciertamente un tema pendiente para el sector ahora gobernante. El mismo Tanco en una entrevista periodística, luego de la contienda electoral, señalaba que "los problemas de Jujuy son la tierra y la vivienda", en clara alusión asimismo a los añejos reclamos de los campesinos arrendatarios puneños. La solución, para el viejo caudillo, residía en recuperar aquellos programas del radicalismo yrigoyenista, referidos a la expropiación y colonización de los latifundios así como impulsar la construcción de viviendas obreras ${ }^{32}$.

Así muchos proyectos del tanquismo, otrora postergados, serían inmediatamente recuperados y enviados para su tratamiento legislativo. Por ello, los primeros meses de gobierno estarían signados por una intensa actividad legislativa, impulsando diversas normas dirigidas a mejorar las endebles áreas de salud, educación y, claro está, vivienda. En esta última

31 Adriana Kindgard, Alianzas y enfrentamientos, 95-98

32 Diario, 24 de febrero de 1947, 18. 
esfera, las principales medidas en las ciudades se vincularían con la edificación estatal de una serie de barrios obreros y el fomento a la construcción particular de casas a través de los créditos baratos otorgados por el Banco Hipotecario Nacional.

Por su parte, la acción oficial en la zona rural se plasmaría en la elaboración de múltiples normas que tratarían tanto la cuestión habitacional como el problema de la tierra. Una herramienta utilizada frecuentemente para enfrentar al latifundio sería el de la expropiación, autorizada por Ley $1865^{33}$. Por medio de la misma, el Estado contaría con un instrumento fundamental para la adquisición de tierras privadas, las cuales, una vez realizada la operación, serían destinadas a la expansión de poblados, la colonización y loteos.

En consonancia con esta medida, se instituía el Código Rural, sancionado como Ley 1896, que a su vez creaba el Consejo Provincial de Colonización. Este organismo actuaría, en concordancia con la labor del Consejo Agrario Nacional, alentando, durante los inicios de la gestión peronista, la propiedad minifundista para la explotación agropecuaria ${ }^{34}$. La venta de lotes de tierras (fiscales o privadas adquiridas por medio de la expropiación), como en gran parte del país, sería realizada con amplias facilidades crediticias para los compradores ${ }^{35}$.

Aunque en este trabajo no evaluamos de forma específica lo logros y lí-

33 Al finalizar la nota el ahora senador nacional sentenciaba: "No se justifica en ninguna forma que cada jujeño no tenga su vivienda. (...) Pueblo que tiene su vivienda propia ya no es un rebaño de ovejas. Por esto la oligarquía en Jujuy no ha construido una sola vivienda obrera. (...) El gobierno debe procurar que cada obrero tenga su vivienda, comenzando con los de menores sueldos que son los más necesitados. Esta debe ser la obra fundamental del gobierno radical si ha de inspirarse en Yrigoyen y marchar al compás de la obra magnífica de nuestro líder el coronel Perón". Álbum del Nuevo Jujuy (Salta: Talleres Gráficos La Provincia, 1946), 47.

34 Ley 1865: De la Expropiación. Jujuy: Ministerio de Hacienda, Agricultura, Industrias y Obras Públicas, 1948), 2-6

35 Según Blacha y Magallán al menos hasta 1949 el Consejo Agrario Nacional facilitaría a los arrendatarios acceder a la propiedad de la tierra, mediante el crédito oficial. Luego, dicha propuesta quedará relegada a un segundo plano, dando paso al interés social que debería cumplir la tierra como generadora de divisas, en una coyuntura económica difícil. Luis Blacha y Maximiliano Magallán, "El Consejo Agrario Nacional y la acción colectiva. Reflexiones socio-históricas sobre las estrategias estatales peronistas (1940-1952)," Estudios Interdisciplinarios de América Latina y el Caribe Vol. 24 $\mathrm{N}^{\circ} 2$ (2013), 150-151. 
mites de esta entidad oficial, nos interesa destacar aquí cómo esta política apuntó a brindar respuestas concretas a la cuestión del latifundio. Asimismo, tendió a aumentar las viviendas unifamiliares en el ámbito rural, dado que se exigía al colono, una vez adquirido el terreno, a edificar una residencia que reuniese las mínimas condiciones de habitabilidad para convivir junto a su familia. Todo ello daba cuenta, una vez más, de la existencia de una agenda social rural del gobierno justicialista, y un claro interés para el tratamiento expeditivo de estas cuestiones.

Otra iniciativa gubernamental importante se orientó a ampliar ciertos poblados que se hallaban encorsetados alrededor de terrenos privados. Un ejemplo de ello lo constituían los pueblos de San Pedro y Ledesma, próximos a los ingenios La Esperanza y Ledesma respectivamente. En ambos casos se hallaban rodeados de las propiedades de aquellos establecimientos pues habían surgido y crecido a la par de la expansión azucarera. De allí las dificultades en su expansión ante el notorio crecimiento poblacional experimentado por entonces.

De esta manera, en San Pedro el gobierno edificaría el barrio obrero Presidente Perón en terrenos expropiados al ingenio La Esperanza. En la localidad de Ledesma, se ejecutaría idéntica acción con el propósito de ampliar la jurisdicción del poblado adyacente. Resulta interesante resaltar como todas estas medidas conllevaron una significativa carga simbólica, pues se aplicaba a aquellas compañías vinculadas a un partido conservador, otrora poseedor del poder político en la provincia. Ello queda claramente patente en las palabras del gobernador Iturbe luego de realizar la expropiación al Ingenio Ledesma en 1949:

"Con la expropiación que acabamos de realizar yo aseguro al Pueblo trabajador que (...) hemos roto por fin y para siempre el feudo capitalista y opresor de Ledesma. El Ingenio Ledesma a través de épocas no por pasadas menos bochornosas se erigía en la zona como el símbolo más desnudo del capitalismo oligárquico. Pero ese predominio prepotente (...) ha terminado para siempre con la llegada de Perón. Este Pueblo no tenía cómo expandirse porque al capitalismo opresor no le interesaba la suerte 
de los trabajadores ni el progreso material del Pueblo que era ahogado entre las trenzas de un feudalismo medieval. La expropiación de estas 34 manzanas (...) tiene para nosotros un gran simbolismo: aparte de quebrantarse la voracidad capitalista, traza la etapa indicativa en que el trabajador puede levantar la mirada bien en alto, porque el pasado tenebroso no volverá jamás ${ }^{36}$."

El recurso de la expropiación para resolver el problema de la tierra en la Puna estaría continuamente en la agenda gubernativa peronista. De hecho constituía uno de los viejos programas del tanquismo y un añejo reclamo de los campesinos arrendatarios. Tras los sucesos acontecidos con la marcha conocida como el Malón de la Paz, Miguel Tanco desde su banca en el Congreso Nacional se abocaría a acelerar el proyecto que atendiese aquella demanda ${ }^{37}$. Recién en 1949, Perón firmaría el solicitado decreto, transformando las propiedades expropiadas en tierras fiscales.

En este marco de intensa actividad estatal, otras iniciativas serían implementadas en la zona rural con el propósito concreto de dotar de viviendas dignas a sus pobladores. Las mismas se orientarían a aquellas áreas cuya actividad económica reunía a una importante cantidad de trabajadores. Nuevamente sus implicancias alcanzarían una notoria resonancia tanto en el plano material como simbólico, pues estaban dirigidas a someter al poder estatal a aquellos establecimientos que supieron ser, hasta no hacía mucho tiempo, emblemas de la poderosa "oligarquía del azúcar".

\section{LA LEY DE VIVIENDA OBRERA EN LA ZONA RURAL}

En el área rural de la provincia, como se ha dicho, el gobierno peronista procuraría atender las necesidades habitacionales de los trabajadores que desarrollaban su actividad en el ámbito privado pero también en la esfera estatal. Un hecho representativo de esto último sería la sanción de la Ley 1885, que obligaba al Estado a dotar de viviendas (destinadas a los maes-

36 Ley 1896: Código Rural (Jujuy: Ministerio de Hacienda, Agricultura, Industrias y Obras Públicas, 1948).

37 Diario Jujuy Jujuy, 13 de marzo de 1949, 2. 
tros) a todos los edificios escolares rurales. El cumplimiento efectivo de dicha medida, junto con la creación de numerosas escuelas a lo largo de este período, tendría a su vez implicancias relevantes en un endeble campo educativo signado por altos niveles de analfabetismo en el distrito jujeño ${ }^{38}$.

De igual modo, la intervención estatal también se orientó hacia la órbita de las grandes empresas que congregaban a una relevante masa laboral. Si bien actividades como la producción minera cumplía tal requisito, fue claro cómo el gobierno apuntó de modo implícito a la agroindustria azucarera, núcleo productivo al que tempranamente prestó especial atención. Ya desde la etapa de intervención precedente, la delegación local de la Secretaría de Trabajo había realizado múltiples inspecciones e informes sobre las condiciones laborales y, especialmente, habitacionales de los obreros de los ingenios ${ }^{39}$.

Luego, con el inicio de la gestión peronista, inmediatamente se promoverían una serie de normas dirigidas a la protección de aquel conjunto laboral, que incluirían amplias áreas, más allá de la vivienda, como la de la salud. Una muestra de ello lo constituiría la sanción de la Ley 1655, que forzaba a los propietarios de los ingenios a prestar en forma gratuita asistencia médico-hospitalaria para todos los trabajadores y sus familias, sean permanentes o temporarios, así como también provisión de leche a la niñez y a la población enferma ${ }^{40}$.

Uno de los impulsores de estas normas fue el ministro de gobierno, José Humberto Martiarena, quien desde su cartera tenía a su cargo las áreas de

38 El Malón de la Paz fue el nombre de la marcha realizada, en mayo de 1946, por un grupo numeroso de campesinos arrendatarios de las tierras altas jujeñas hacia Capital Federal con el propósito de solicitar a Perón los títulos de propiedad de las tierras que ocupaban. Al llegar, fueron saludados por el presidente y conducidos luego al Hotel de Inmigrantes, donde permanecerían unos días hasta su súbita y violenta deportación. Volvían al altiplano con las manos vacías. Para ampliar acerca de esta temática véase Elena Belli. Ricardo Slavutsky y Pantaleón Rueda (edits.), Malón de la Paz, una historia, un camino (Buenos Aires: Universidad de Buenos Aires, 2007). 111-135 y Adriana Kindgard, "Tradición y conflicto social en los Andes argentinos: en torno al Malón de la Paz de 1946", Estudios Interdisciplinarios de América Latina y El Caribe Vol. $15 \mathrm{~N}^{\circ} 1$ (2004): 71.

39 Revista 4 Años de Gobierno (1946-1950). (Jujuy: Imprenta del Estado, 1950), 52.

40 Jujuy. Intervención Federal: Seis meses de gobierno (Jujuy: Imprenta Kraft, 1945), 26. 
justicia, educación y salud. Este abogado, de 32 años de edad al asumir como funcionario en la gestión peronista, era un miembro de aquel grupo de jóvenes dirigentes que Tanco, hacía un tiempo, había incorporado a sus filas. Como muchos de sus compañeros de partido formó parte de aquella administración de facto abierta en 1943, siendo en ese entonces además secretario y apoderado de la Unión Cívica Radical Yrigoyenista ${ }^{41}$.

A poco de iniciarse el gobierno de Iturbe, aquel flamante ministro de gobierno participaría activamente en la elaboración de varios proyectos legislativos de tinte social que adquirirían una significativa relevancia. Si bien gran parte reconocían sus orígenes en viejos programas del tanquismo, fue claro cómo este funcionario los reformuló y se encargó de que fuesen prontamente tratados. En esta labor, la vivienda de los trabajadores rurales constituiría uno de los temas al que Martiarena le prestaría especial interés.

En efecto, a fines de 1947 se presentaba el proyecto que trataba dicho asunto, siendo aprobado como Ley 1814, bajo la denominación ley de vivienda obrera. La misma obligaba a todos los establecimientos o empresas de propiedad privada, instalados en el distrito jujeño, a proporcionar vivienda cómoda e higiénica a su personal de empleados y a sus familias, sean permanentes o transitorios. El Ejecutivo sería el encargado de establecer los plazos para la ejecución de esta norma y de controlar su cumplimiento en la provincia ${ }^{42}$. Cabe destacar la relevancia y trascendencia de esta ley, pues no hubo a nivel nacional una normativa similar, específica y diferenciada sobre la vivienda rural, más allá de la incluida en el interior de ciertas legislaciones, como la de Arrendamiento o el Estatuto del Peón.

Para la edificación de estas casas, las empresas debían evitar el hacinamiento y la promiscuidad, asegurando una vida familiar saludable y decente. Estas unidades, además de reunir condiciones mínimas de abrigo, aireación y luz natural, no podrían ser utilizadas para ningún otro fin que la de

41 Quedaban incluidos en esta norma todos los establecimientos comerciales e industriales que reuniese a un personal no inferior a doscientas personas. Diario de Sesiones de la Legislatura de Jujuy, 10 de julio de 1946.

42 Marcelo Jerez, "Peronismo y juventud en el Noroeste Argentino. Alberto Iturbe y la joven dirigencia política en la conformación del primer peronismo en Jujuy”, Estudios Sociales Vol. 47 (2014): 85. 
alojamiento para el personal y sus familias. Asimismo se advertía que los ocupantes de estas viviendas debían responder en caso de daños o deterioros que resultasen de su uso incorrecto.

Similares condiciones habitacionales también eran exigidas para aquel personal que revestía el carácter de transitorio. Igualmente, se imponía a los establecimientos afectados comunicar al gobierno en el lapso de 15 días los aumentos de personal. Por su parte, la ley designaba como entidades encargadas de evaluar los planos de las nuevas edificaciones a la Dirección de Sanidad y la de Arquitectura, cuyos informes serían elevados al Poder Ejecutivo para su definitiva aprobación.

La violación de esta norma establecía una multa que iba entre los $\$ 1.000$ a $\$ 50.000 \mathrm{~m} / \mathrm{n}$. En todos los casos se permitiría el descargo (admitida como prueba) del infractor. El Ejecutivo aplicaría esta sanción y su cobro se realizaría por vía de apremio, una vez establecida la misma no podría ser exonerada; "bajo pena de responder personalmente los funcionarios que las autoricen”. Finalmente, así también se contemplaba el caso de los infractores reincidentes, es decir aquellos que vencido el plazo establecido no dieran cumplimiento con sus obligaciones ${ }^{43}$.

Al momento de presentarse el texto de esta ley en el recinto legislativo, su tratamiento no requirió mayores debates y sería aprobado sin observación. Aunque esto no resulta extraño en un parlamento con mayoría oficialista como el de Jujuy, es interesante destacar que el proyecto no ameritó ninguna discusión previa. Ello seguramente respondió a que no se trataba de un programa que los diputados presentes desconocieran, sino más bien de un viejo anhelo de aquel grupo tanquista que poblaba en su mayoría la Legislatura.

Una vez sancionada esta norma, los medios escritos de comunicación la reproducirían con beneplácito en sus páginas. Felicitando al Ejecutivo como responsable de su formulación, resaltaban los beneficios que

43 La Ley 1814 fue tratada en la Legislatura provincial a fines de 1947 y sancionada a comienzos del año siguiente. Diario de Sesiones de la Legislatura de Jujuy, 20 de diciembre de 1947, 28-30. 
emanaría de su aplicación, sin ahorrar críticas a las pésimas condiciones habitacionales que durante mucho tiempo ciertas empresas habían hecho padecer a sus obreros. En sus artículos no dejaban de identificar a dichos establecimientos como "los más ricos de la provincia", haciendo implícita referencia a los ingenios azucareros:

"[Con la presente ley] se aspira a que todo trabajador tenga una vivienda digna que le permita vivir como un ser humano y no en las condiciones en que a veces habitan en algunos establecimientos que se encuentran entre los más ricos de la provincia y a cuya riqueza contribuyen con su trabajo y con su esfuerzo millares de obreros que viven en su mayoría en las peores condiciones que es dable imaginar ${ }^{44}$."

Pese a la relevancia y amplitud de esta medida, seis meses después otra norma sería creada para complementarla. A mediados de 1948 se sancionaba la Ley 1860 que declaraba la obligatoriedad de "las fábricas azucareras y demás establecimientos industriales" de la provincia de proveer agua potable y servicios sanitarios a las viviendas de sus trabajadores ${ }^{45}$. Pero, más allá de lo concreto de estos propósitos, resulta interesante señalar que estas disposiciones se hallaban ya contempladas en el artículo segundo de la Ley 1814.

La instauración de esta nueva norma tal vez se vinculaba con la alusión específica que hacía a las "fábricas azucareras", referencia ausente en la anterior ley donde se hacía mención a las empresas en general. Ello daría cuenta de la intención oficial de identificar con claridad a quiénes se constituirían en los principales responsables de la edificación de la vivienda obrera rural y de la dotación de todos sus servicios, confirmando una vez más en forma lisa y llana hacia quiénes estaba destinada la reglamentación.

Este supuesto se refuerza si tenemos en cuenta que el diputado que presentaba aquel proyecto en la Legislatura, Vicente Filardi, representaba al

44 Diario de Sesiones de la Legislatura de Jujuy, 20 de diciembre de 1947, 29.

45 Revista 4 de Junio (Jujuy: Imprenta del Estado, 1949), 7. 
departamento Ledesma y había sido además el médico encargado de controlar en el área azucarera el cumplimiento de la Ley 1655, desde su creación en el año 1946. Su profesión y la experiencia desarrollada en aquella zona contribuyeron sin duda a impulsar la sanción de la Ley 1860 como una medida tendiente a fortalecer la labor social que venía desenvolviendo el gobierno.

Oriundo de la región azucarera, Filardi, que había asumido como diputado provincial en 1948, por las funciones que le había tocado desarrollar era un gran conocedor de las pésimas condiciones habitacionales y sanitarias de los trabajadores de los ingenios. Al momento de presentar dicho proyecto al resto de los legisladores, expresaba que él mismo tenía como objetivo ampliar los alcances de la ley de vivienda obrera, evitando así los peligros para la salud de aquella densa masa laboral.

En su fundamentación, este galeno también hacía referencia a su experiencia como empleado jerárquico del Departamento de Sanidad, responsable del cumplimiento de la prestación gratuita de los servicios sanitarios por parte de los establecimientos industriales. Allí había podido comprobar, desde los inicios del gobierno peronista, la penosa realidad existente ante la tan deficiente provisión de un elemento tan esencial como el agua potable. Así este diputado relataba:

"En mis viajes realizados he podido sorprender y constatar hechos que agravian a la civilización. ¿Cómo es posible señor Presidente que hombres, mujeres y niños, que vuelven agobiados a sus hogares bajo el peso y la fatiga de la tarea diaria, deban beber de la misma fuente donde abrevan los animales del trabajo, donde ellos mismos realizan algunas elementales obligaciones de higiene? ¿De acequias que muchas veces, por falta temporaria de agua corriente se convierten en estercoleros y lugares donde se arrojan los desperdicios? ${ }^{46}$."

Por su parte, en las tierras altas de la provincia, las empresas mineras, que

46 Diario de Sesiones de la Legislatura de Jujuy, 22 de junio de 1948,159. 
desde las primeras décadas del siglo XX exhibían un creciente desarrollo, también debieron adecuarse a estas normas. Su cumplimiento, contribuiría a mejorar lo que hasta ese momento eran precarios campamentos existentes alrededor de los centros mineros, para constituirlos y consolidarlos como poblados integrados por viviendas medianamente confortables y dotadas con servicios urbanos básicos.

Los medios de comunicación así como ciertos documentos oficiales, continuamente destacaban los avances obtenidos en ese sentido, a partir de los favorables informes de los inspectores oficiales que frecuentemente controlaban en aquellos núcleos productivos la aplicación efectiva de la normativa vigente. Similares resultados, asimismo, se lograron de la asidua vigilancia por el cumplimiento de la Ley 1655, en cuya tarea intervenían agentes vinculados a la agencia estatal de sanidad ${ }^{47}$.

$\mathrm{Al}$ respecto resulta ilustrativo el testimonio de un trabajador y dirigente gremial de la mina El Aguilar, Reinerio Cruz, quien, un año antes de finalizar la experiencia peronista, en una nota periodística hacía una evaluación de los logros obtenidos con aquellas medidas sociales impulsadas desde el gobierno. Entre ellas, destacaba no solo los avances en el campo salarial, sino también en las condiciones de vida del minero: becas de estudio para sus hijos, asistencia médica gratuita, sin dejar de mencionar, por supuesto, los beneficios alcanzados con la provisión de la vivienda digna ${ }^{48}$.

Pero la implementación de esta política social naturalmente no estuvo exenta de tensiones con las empresas privadas involucradas, sobre todo con los establecimientos azucareros, cuyos propietarios supieron ser dueños indiscutibles del poder político. En tal sentido, y de acuerdo a las fuentes trabajadas, aunque en líneas generales aquellas compañías cumplieron con dichas normas a lo largo de este período, para ello fue asimismo necesario un constante y rígido control estatal. Sin duda, la aceptación de aquellas reglamentaciones no era para nada voluntaria, ni libre de ciertas

47 .Diario de Sesiones de la Legislatura de Jujuy, 22 de junio de 1948, 155-156.

48 Diario Jujuy Jujuy, 10 de mayo de 1950; 11 de febrero de 1953; 8 de junio de 1953; Mensaje del Gobernador Jorge Villafañe, $1^{\circ}$ de mayo de 1953 (Jujuy: Imprenta del Estado, 1953). 
inobservancias cuando se presentaba la mínima oportunidad.

En uno de sus últimos discursos ante la Legislatura, el gobernador Villafañe daba cuenta de esta persistente tarea oficial. Así, tanto para el cumplimiento de las leyes 1814 y 1860, el mandatario provincial esgrimía que se continuaba con la inspección de las viviendas obreras en la zona rural que reuniesen condiciones mínimas de habitabilidad y que contasen con los servicios sanitarios esenciales, principalmente en los establecimientos azucareros y mineros. De igual modo, en estas áreas productivas, se vigilaba el acatamiento de la Ley 1655 relativo a la prestación de servicios médicos a los trabajadores ${ }^{49}$.

Con todo, debe señalarse que esta norma, pese a su importancia, parece no haber sido suficiente para solucionar el problema de la vivienda obrera en los ingenios. Ello en buena medida se debía a aquellas fisuras por donde filtraba el incumplimiento de estos establecimientos. En 1950, Eva Perón, ante la visita de una delegación de obreros del azúcar de Jujuy que habían participado de los actos del día de la Lealtad en la capital de la Nación, manifestaba conocer aquel padecimiento y que la Fundación que presidía colaboraría en poco tiempo con la construcción de una serie de casas económicas ${ }^{50}$.

En los albores del derrocamiento de este gobierno popular, una de las medidas tendientes a reforzar la tarea de controlar las disposiciones vigentes con respecto a la vivienda obrera fue la sanción de la Ley 2345. Bajo la denominación Ley Provincial de Vivienda, se creaba el Instituto de la Vivienda que dependería del Ministerio de Hacienda, Economía, Obras Públicas y Previsión Social. Entre sus principales funciones se hallaba la planificación y promoción de todo tipo de unidades destinadas a trabajadores "en situación de desamparo o de inferioridad económica" 51 .

Si bien gran parte de las facultades de esta entidad se vinculaban con el ámbito urbano, también tendría injerencia en la zona rural, especialmente

49 Diario Jujuy, Jujuy, 23 de marzo de 1954, 5.

50 Mensaje del Gobernador Jorge Villafañe,

51 Diario Jujuy Jujuy, 1 de noviembre del 1950. 
en fortalecer la presencia estatal para vigilar el cumplimiento de las reglamentaciones vigentes. En efecto, una de sus tareas esenciales sería la de inspeccionar las casas edificadas tanto por la acción gubernamental como privada en toda la jurisdicción provincial, constituyéndose a partir de entonces en el principal organismo responsable del cumplimiento de las leyes asociadas a la vivienda obrera rural ${ }^{52}$.

Con el fin de la administración peronista, si bien gran parte de la legislación social se mantendría en los gobiernos subsiguientes, otro tanto acontecería con los incumplimientos y tensiones que ello generaría sobre todo en el ámbito rural de la provincia. Indudablemente otra etapa emergía signada por coyunturas políticas y económicas diferentes, nuevos actores y renovadas luchas, pero donde los reclamos por mejores condiciones de vida $y$, principalmente, por óptimas condiciones habitacionales continuarían en aquellas paradigmáticas zonas productivas de este distrito del Noroeste argentino.

\section{Reflexiones Finales}

En este trabajo hemos propuesto un análisis de la legislación del gobierno peronista vinculada a la vivienda rural en Jujuy, la cual, por un lado, fue heredera de programas sociales diseñados en el lapso precedente, y por otro lado, constituyó una normativa claramente diferenciada de aquella implementada en el espacio urbano. Ello se debió principalmente a las características propias que presentaba dicha área al iniciarse esa gestión popular; signada por la presencia de importantes latifundios, viejos reclamos en torno a la cuestión de la tierra y las deplorables condiciones laborales y de vida en los centros mineros $y$, sobre todo, azucareros.

Estas problemáticas estuvieron presentes en la plataforma del tanquismo desde la etapa previa al surgimiento del peronismo, período de una dura rivalidad política con un conservadurismo local muy vinculado con los ingenios azucareros. Fue en estos años cuando aquel grupo político comenzó a hacerse eco de las demandas de los sectores laborales más humil-

52 Diario Jujuy Jujuy, 4 de junio de 1955, 5. 
des, a erigir como banderas propias los reclamos populares, y a diagramar las primeras iniciativas tendientes a paliar aquella realidad de la población rural jujeña.

Luego, con el inicio de la experiencia justicialista, estos programas serían recuperados, reformulados y plasmados en una legislación, constituyéndose en la modalidad de intervención más significativa de esta gestión y de notoria resonancia en el campo social. Ello revelaría ciertas permanencias en el campo de las políticas públicas, tanto en una como en otra etapa, más allá de la ruptura que el peronismo, en este y otros ámbitos, más tarde buscaría afanosamente establecer con el período precedente.

Estas líneas de continuidades también se reflejarían en la actividad política de aquellas autoridades peronistas. Y es aquí precisamente donde resalta un aspecto distintivo relevante: a diferencia de otros dirigentes provinciales, especialmente de aquellos distritos vecinos ${ }^{53}$, aquí la cúpula principal del tanquismo tempranamente tuvo una activa participación en el diseño de políticas sociales que luego, una vez en el gobierno, ellos mismos las ejecutarían aunque, claro está, en un nuevo marco político.

Figuras como Tanco, Iturbe y Martiarena constituirían algunos de los actores políticos que más sobresaldrían en ese sentido. Este último, precisamente, cumpliría un rol destacado en la elaboración de diversas normas con un alto contenido social, orientadas a atender las necesidades más acuciantes de los sectores más sumergidos. El nivel de consenso alcanzado en esta tarea respondió en gran medida a la mayoría oficialista existente en la legislatura local, donde los partidos antiperonistas, en las elecciones de 1946, no ubicaron ni un solo representante. Buena parte de estos proyectos buscarían mejorar áreas muy críticas por entonces, como las de educación, salud y vivienda.

En efecto, en el plano habitacional, las políticas implementadas fueron diversas. Pero mientras en los centros urbanos las medidas oficiales más salientes se orientaron a la construcción estatal de viviendas, en la zona rural se delegó esta tarea a los establecimientos privados que reunían a una

53 .Diario de Sesiones de la Legislatura de Jujuy, 13 de julio de 1955, 163. 
importante cantidad de trabajadores. Así, fue evidente como en el caso abordado en este estudio, el Estado tendió a descentralizar su política social, confiriendo a aquellas compañías el financiamiento y la construcción de la vivienda obrera.

La sanción de la Ley 1814 fue representativa de esta posición oficial. Para varios trabajadores su aplicación implicó, a través de líneas crediticias acordadas con la empresa, la obtención de la casa propia, para otros tantos, especialmente los obreros temporarios de la zona azucarera, conllevó mejoras sustanciales en sus condiciones habitacionales. La formulación de esta norma, asimismo, no estuvo exenta de revisiones, correcciones y ajustes con el propósito de reforzar la intervención estatal en aquellos importantes "enclaves". Al respecto, la aprobación de la Ley 1860 no solo complementaría la anterior norma, refrendando los requerimientos en la provisión de servicios sanitarios básicos, sino que reafirmaría una vez más hacia quiénes estaba dirigida esencialmente toda esta reglamentación.

En tal sentido, si bien la legislación involucraba a todas las grandes empresas instaladas en la provincia, entre ellas las mineras, fue claro cómo los ingenios azucareros se constituyeron en sus principales destinatarios. Evidentemente esta actividad era la que reunía a la masa laboral más importante del distrito, cuyas condiciones habitacionales eran ciertamente deplorables, no obstante, también debe señalarse que la aplicación de esta medida también mostraba su trasfondo político.

No solo los ingenios azucareros estaban vinculados a un grupo político que otrora había monopolizado el gobierno de la provincia sino que, durante mucho tiempo, se había constituido en un férreo adversario del ahora sector gobernante. Esto contribuyó a que en la conformación del peronismo en Jujuy resaltara tanto el escaso tránsito de conservadores a la fuerza liderada por Tanco, como el rechazo de cualquier posibilidad de alianza entre ambos sectores. En este escenario, de bandos tan claramente enfrentados, las medidas que nos ocupan tuvieron indudablemente significativas implicancias tanto en el plano político como simbólico.

En este contexto, es dable suponer las tensiones generadas por la resistencia de los ingenios azucareros a la legislación social impuesta por el gobier- 
no peronista, lo que se plasmaba, principalmente, en los evidentes intentos por evadir su cumplimiento. Develar las especificidades de estos conflictos, por otro lado, excede los propósitos de este trabajo y requiere de un análisis más amplio que dejaremos pendiente para una investigación futura. Por lo pronto, nos interesa destacar aquí el fuerte y constante control estatal, asiduamente esgrimido por las propias autoridades provinciales, lo que conllevaría asimismo a la creación de nuevos organismos oficiales que asegurasen el normal acatamiento de aquellas normativas.

No obstante, las fuentes analizadas dan cuenta de la pervivencia de esta problemática así como de la compleja labor de someter aquellos establecimientos al poder estatal. Los datos del censo relevado en 1960 develan que Jujuy ocupaba el noveno lugar con mejor relación unidad de vivienda/ persona dentro de las veintitrés jurisdicciones. En su interior, similares óptimos guarismos exhibían la zona minera y, en el área azucarera, San Pedro. Sin embargo, en este marco, resulta interesante señalar cómo Ledesma, pese a mejorar sus valores con respecto al relevamiento de 1947, aún mostraba los peores índices de la provincia ${ }^{54}$.

Pero si bien dicha cuestión no constituyó una tarea fácil de resolver, es dable resaltar cómo aquel sector político justicialista logró diseñar una legislación específica destinada a atender las demandas sociales del ámbito rural, tales como el de la vivienda obrera. De este modo, aunque en este trabajo quedan varios elementos por profundizar o indagar, con lo hasta aquí examinado creemos haber avanzado sobre los rasgos de una política social hasta entonces inédita en la provincia y en la legislación nacional de la época. Dejamos planteado, por último, el interrogante de si acaso similares medidas estatales fueron aplicadas en otros distritos provinciales. Lo cierto es que en Jujuy, su trascendencia conllevó a que configurara por mucho tiempo una hoja de ruta que gobiernos posteriores procurarían seguir y profundizar.

54 En el departamento Capital la proporción de habitantes por unidad de vivienda era de 5 mientras en los departamentos donde se hallaban los centros mineros en promedio el valor descendía a 3,5, en San Pedro a 4,4, mientras en Ledesma ascendía a 7,5. Censo Nacional de Vivienda del año 1960. (Buenos Aires, 1961). 


\section{Bibliografía}

\section{Fuentes primarias}

\section{Archivos}

\section{Archivo General de la Nación}

Censo General de la Nación, año 1947. Censo de Población. Buenos Aires, 1951.

IV Censo Escolar, del Analfabetismo y de la Vivienda del año 1943. Buenos Aires, 1948.

Censo Nacional de Vivienda del año 1960. Buenos Aires, 1961.

\section{Archivo de la Legislatura de Jujuy}

Diario de Sesiones de la Honorable Legislatura de Jujuy, años 1946-1955.

Ley 1865: De la Expropiación. Jujuy: Ministerio de Hacienda, Agricultura, Industrias y Obras Públicas, 1948.

Ley 1896: Código Rural. Jujuy: Ministerio de Hacienda, Agricultura, Industrias y Obras Públicas, 1948.

\section{Archivo Histórico de Jujuy}

Mensaje del Gobernador Jorge Villafañe, $1^{\circ}$ de mayo de 1953. Jujuy: Imprenta del Estado, 1953.

\section{Publicaciones periódicas}

Diario Crónica Jujuy, 1943.

Diario La Vanguardia Jujuy, 1930.

Diario Jujuy Jujuy, 1947, 1948,1949.

Revista 4 Años de Gobierno (1946-1950). Jujuy: Imprenta del Estado, 1950.

Revista 4 de Junio. Jujuy: Imprenta del Estado, 1949.

Revista Gobierno y Soberanía.Vol. S/1. S/e, 1949.

\section{Libros}

Jujuy. Intervención Federal: Seis meses de gobierno. Jujuy: Imprenta Kraft, 1945.

324 Álbum del Nuevo Jujuy. Salta: Talleres Gráficos La Provincia, 1946.

Hidalgo, Rubén e Ignacio Martínez Loran. Familia y tradición en el Norte argentino. Buenos Aires: Editorial Provincias Argentinas, 1964. 


\section{Fuentes secundarias}

Aboy, Rosa. Viviendas para el pueblo. Espacio urbano y sociabilidad en el barrio de Los Perales. 1946-1955. Buenos Aires: Fondo de Cultura Económica, 2005.

Armus, Diego y Susana Belmartino,. "Enfermedades, médicos y cultura higiénica”. En Nueva Historia Argentina. Crisis económica, avance del Estado e incertidumbre política (1930-1943), dirigido por Alejandro Cattaruzza. Buenos Aires: Sudamericana, 2001, 283-329.

Ballent, Anahí. Las huellas de la política. Vivienda, ciudad, peronismo en Buenos Aires. 1943- 1955. Buenos Aires: Universidad Nacional de Quilmes-Prometeo, 2005.

Belli, Elena, Ricardo Slavutsky y Pantaleón Rueda (edits.). Malón de la Paz, una historia, un camino. Buenos Aires: Universidad de Buenos Aires, 2007.

Blacha, Luis y Maximiliano Magallán. "El Consejo Agrario Nacional y la acción colectiva. Reflexiones socio-históricas sobre las estrategias estatales peronistas (1940-1952)". Estudios Interdisciplinarios de América Latina y el Caribe. Vol. 24. N 2 (2013): 131-155.

Campi, Daniel y Marcelo.Lagos, "Auge azucarero y mercado de trabajo en el Noroeste Argentino, 1850-1930”. Revista Andes. Nº 6 (1995): 179-208.

Campi, Daniel. "Contrastes cotidianos. Os engenhos açucareiros do norte da Argentina como complexos sócio-culturais". Varia Historia. Vol. 25 (2009): 245-267.

Fleitas, María Silvia. "Reforma? Revolución? En torno a la lucha política a fines de la década radical en Jujuy". En Del Centenario al peronismo. Dimensiones de la vida política argentina, compilado por María Inés Tato y Martín Castro. Buenos Aires: Imago Mundi, 2010, 129-156.

Jerez, Marcelo. “El gobierno de Alberto Iturbe (1946-1952): La política de vivienda del primer peronismo en Jujuy". Revista Cuadernos, $\mathrm{N}^{\circ} 41$ (2012): 293-313.

Jerez, Marcelo. "Características habitacionales en Jujuy, Argentina, en la primera mitad del siglo XX". Revista América Latina en la Historia Económica, N² (2012): 163-191.

Jerez, Marcelo. "Notas críticas en torno a la política habitacional del primer peronismo en Jujuy (1946-1955)". Revista de Estudios Marítimos y Sociales, N 5/6 (2013): 129-139. 
Jerez, Marcelo. "Peronismo y juventud en el Noroeste Argentino. Alberto Iturbe y la joven dirigencia política en la conformación del primer peronismo en Jujuy". Estudios Sociales. Vol. 47 (2014): 69-92.

Jerez, Marcelo. "Proyectos, debates y críticas en torno a la vivienda obrera en el Noroeste argentino. San Salvador de Jujuy (1930-1945)". VI Anuario de la Escuela de Historia Virtual. No 6 (2014): 90-108.

Kindgard, Adriana. "Tradición y conflicto social en los Andes argentinos: en torno al Malón de la Paz de 1946". Estudios Interdisciplinarios de América Latina y El Caribe, Vol. 15. No 1 (2004): 71-94.

Kindgard, Adriana. Alianzas y enfrentamientos en los orígenes del peronismo jujeño. Jujuy: Ediunju, 2001.

Lagos, Marcelo. "El mundo del trabajo en los Ingenios azucareros en la etapa de inserción al mercado nacional (1920-1940)". En Jujuy: arqueología, historia, economía, sociedad, compilado por Daniel Santamaría. Jujuy: Ediciones Cuadernos del Duende, 2005, 320-343.

Ortiz Bergia, María José. "Casas para los trabajadores. Los planes estatales de vivienda social en la Córdoba peronista". Coordenadas. Revista de Historia Local y Regional Vol. 1 (2014): 273-296.

Rigotti, Ana María. Vivienda para los trabajadores. El municipio de Rosario frente a la cuestión social. Rosario: Prohistoria, 2011.

Santamaría, Daniel. Azúcar y sociedad en el Noroeste argentino. Buenos Aires: IDES, 1986.

Teruel, Ana; Marcelo Lagos, y Leonor Peirotti,. "Los valles orientales subtropicales: frontera, modernización azucarera y crisis". En Jujuy en la Historia. De la colonia al siglo XX, dirigido por Ana Teruel y Marcelo Lagos. Jujuy: Ediunju, 2006, 435-464.

Teruel, Ana y María Teresa Bovi, "El ordenamiento de la propiedad territorial en Jujuy. Del antiguo régimen a la modernidad". En Problemas nacionales en escalas locales. Instituciones, actores y prácticas de la modernidad en Jujuy, dirigido por Ana Teruel. Rosario: Prohistoria, 2010, 93-124.

Para citar este artículo: Jerez, Marcelo. “"Los problemas de Jujuy son la tierra y la vivienda." La ley de vivienda obrera rural durante el primer peronismo en Jujuy (Argentina)", Historia Caribe Vol. XII No. 31 (Julio-Diciembre 2017): 293-326. DOI: http://dx.doi.org/10.15648/hc.31.2017.10 